\title{
INTEGRATED CARE Embedded geriatric surgical liaison is associated with reduced inpatient length of stay in older patients admitted for gastrointestinal surgery
}

\author{
Authors: David Shipway, ${ }^{A}$ Louis Koizia, ${ }^{B}$ Nick Winterkorn, ${ }^{C}$ Michael Fertleman, ${ }^{D}$ Paul Ziprin ${ }^{\mathrm{E}}$ and Krishna Moorthy ${ }^{\mathrm{F}}$
}

The older surgical patient is well known to be at high risk of increased mortality and medical complications in the perioperative period. These occur due to a variety of patient and service related factors. The need for physician support is recognised and liaison models of care can reduce complications and length of stay (LOS) in some surgical specialties. Limited evidence exists evaluating their role in emergency and planned gastrointestinal surgery.

We aimed to establish and evaluate a geriatric surgical liaison service for emergency and elective gastrointestinal surgery. We found that embedded geriatrician liaison and process change throughout the surgical pathway was associated with a mean LOS reduction of 3.1 days for all surgical patients aged $>60$ years $(p=0.007)$. Mean LOS reduction for emergency surgical admissions aged $>60$ was 4.4 days $(p=0.005)$.

Embedded geriatric surgical liaison models of care can be successfully adapted for emergency general and gastrointestinal surgery. In times of financial constraint, reductions in LOS may make modest investment in similar services economically viable.

KEYWORDS: Elderly, emergency surgery, gastrointestinal surgery, service development, liaison

\section{Introduction}

The demographics of global population ageing are well known and yet remain striking. In the next few decades, a 50\% increase

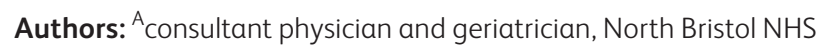
Trust, Bristol, UK; ${ }^{B}$ specialty trainee in geriatric medicine, Imperial College Healthcare NHS Trust, London, UK; ${ }^{C}$ specialty trainee in geriatric medicine, Imperial College Healthcare NHS Trust, London, UK; ${ }^{D}$ consultant physician and geriatrician, Imperial College Healthcare NHS Trust, London, UK and honorary senior clinical

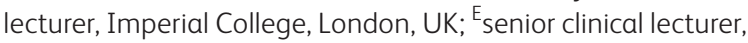
Imperial College London, London, UK and honorary consultant colorectal surgeon, Imperial College Healthcare NHS Trust, London, UK; F senior clinical lecturer, Imperial College London and honorary consultant oesophagogastric surgeon, Imperial College Healthcare NHS Trust, London, UK in the oldest old (aged $>85$ years) is projected, ${ }^{1}$ with similar patterns emerging globally. Advancing age is linked with the accumulation of chronic illness. ${ }^{2}$ This leads to medical complexity through multimorbidity. Additionally, the progressive physiological changes that are seen with ageing predispose older patients to homeostenosis. This loss of physiological reserve is the crux of the frailty syndrome, which is increasingly common and clinically relevant in the oldest old. ${ }^{3}$

These ageing processes and their outcomes are well recognised within the specialties of geriatric and internal medicine, who typically manage an increasingly elderly case mix. However, it is important to recognise that the sequelae of population ageing are not restricted to the specialties of general internal medicine (GIM); many clinical specialties are facing the challenges of an ageing population.

Surgical specialties are particularly challenged by this change in their patient population. Firstly, the neoplastic and degenerative pathologies that form a major part of elective and emergency surgical practice are associated with advancing age. Historic ageism has previously had effects on access to surgery for older patients, but these attitudes are evolving with changes in public expectation. It is therefore inevitable that surgeons will be increasingly asked to operate on increasingly frail and comorbid patients. ${ }^{4,5}$

Secondly, surgical training and practices are changing. In particular, shortened surgical training has had an impact. A recent survey determined that over two-thirds of UK surgical trainees felt training in perioperative medicine was inadequate. The survey also determined that approximately $85 \%$ of surgical trainees thought support from geriatric medicine was necessary, but that in the majority of cases it was inadequate. ${ }^{6}$ Surgical teams face difficulties in managing complex older patients and the literature clearly describes increased rates of postoperative complications (and in particular medical complications), functional decline and mortality with increasing age. ${ }^{7,8}$ Issues describing problems with the organisation of surgical services are well-documented in reports from the Royal College of Surgeons, national audits and patient safety bodies such as the National Confidential Enquiry into Patient Outcomes and Death. ${ }^{4,9-11}$ The synergistic effect of patient and service related factors leads to complications, delayed discharges and increased length of stay (LOS). This places huge pressures on patient flow and has been implicated in the cancellation of planned surgery. 
These issues raise many questions about how physicians with expertise in the management of complex elderly patients can support surgical services to improve outcomes. While some may argue that it is the responsibility of surgeons to adapt to the changing population, increasing consensus recognises that remaining in a medicine vs surgery silo mentality will not solve the problems faced in 21st century healthcare. Collaborative models of care are required to meet the needs of patients who resist traditional categorisation, and are therefore the shared responsibility of surgeons and physicians. ${ }^{12,13}$

\section{Aims}

As with many NHS trusts in the UK, our organisation has faced difficulties with the management and discharge of complex older surgical patients. One key metric illustrating these difficulties has been long LOS. ${ }^{14}$ This has had repercussions on patient flow and led to cancellations of elective surgery. We set out to establish an embedded geriatric medicine liaison service within acute general and gastrointestinal surgery with the aim of reducing inpatient surgical LOS. The design of this service was inspired by similar services for which there is an established evidence base. These include the 'Proactive care of the Older Person undergoing Surgery' (POPS) and the 'Ortho-Geriatric' models of care. ${ }^{15-17}$

\section{Intervention}

Prior to the establishment of this service, no dedicated medical support was provided to the surgical service to assist before and after surgery. Where concerns regarding fitness for surgery were raised, anaesthetic review or specialist medical referral was requested on an ad hoc basis. Postoperatively, reactive medical review for complications was requested via specialty medical referral or via the on call medical registrar. No formal discharge planning meetings took place. There was no process for selection of older patients for post-surgical rehabilitation, and ad hoc referrals were made as required.

\section{Service structure}

The model of care has four key components, as illustrated in Fig 1.

1 Preoperative Comprehensive Geriatric Assessment (CGA) clinic Open access referral is accepted from surgeons, anaesthetists, cancer clinical nurse specialists or pre-assessment clinic. No age limit is mandated. Criteria for referral include perceived frailty, multimorbidity or any other concern about suitability or safety of surgery.

The clinic serves two functions. The first of these is to support surgical decision making in patients considered questionably fit for surgery. Robust assessment is achieved through CGA methodology, which is the cornerstone of evidence-based geriatric medicine. ${ }^{18,19}$ CGA assesses patients holistically across a range of domains using validated tools and scales. The tools selected for our version of CGA (listed in Table 1) were drawn from those used in a successful surgical liaison service with an established evidence base. ${ }^{15}$ The information derived from CGA can then be used to inform surgeons, patients and relatives of a personalised risk profile.

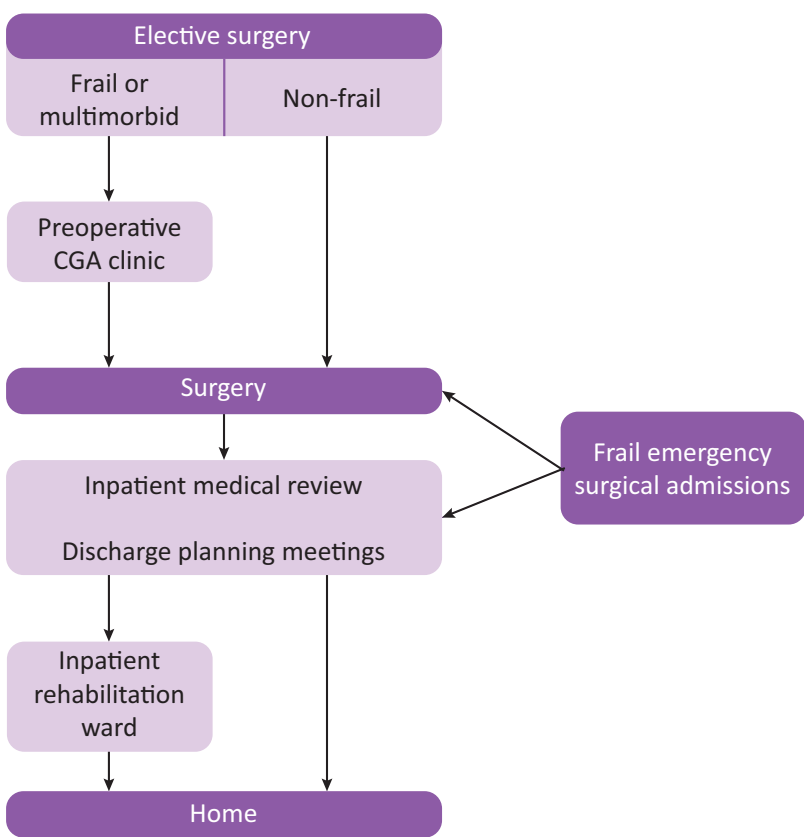

Fig 1. Model of care - embedded geriatric surgical liaison. CGA = Comprehensive Geriatric Assessment

Secondly, CGA identifies targets for medical intervention. This allows construction of a personalised multicomponent intervention tailored to the needs of each patient.

Components of CGA are illustrated in Table 1, and these are contextualised to the forthcoming surgical admission, recovery and rehabilitation. Success of CGA depends on execution of the multicomponent interventions. The outcome of CGA assessment is communicated directly to the patient and operating surgeon and a comprehensive letter including a perioperative plan of management of medical issues is generated for distribution among the surgical, nursing and anaesthetic teams. Electronic note programs permit immediate upload and high visibility of this document.

2 Postoperative medical-surgical ward rounds Twice-weekly ward rounds are conducted on selected patients by a consultant geriatrician accompanied by members of the surgical team. Patients requiring review are identified by medical, surgical, nursing and therapy staff on an open-access non-age-based policy. Indicators for medical review may include advanced age, severity of acute illness, post-operative complications, failure to recover rapidly or discharge delays. The liaison team also has an open access 'first responder' policy for issues arising during working hours outside of ward rounds. This aims to achieve prompt and contextual senior medical input whenever required.

3 Postoperative discharge planning meetings Twice-weekly multidisciplinary team meetings are held to plan discharges. Attendees include a consultant geriatrician, members of the surgical team (ranging from foundation year 1 [FY1] to specialist registrar [SpR]), ward sister, occupational therapist, physiotherapist and discharge coordinator. This meeting identifies barriers to discharge and delegates responsibility to team 
Table 1. Comprehensive Geriatric Assessment

\begin{tabular}{|c|c|c|}
\hline Component & Tool & $\begin{array}{l}\text { Example } \\
\text { intervention }\end{array}$ \\
\hline Comorbidity & $\begin{array}{l}\text { Full history and } \\
\text { itemised optimisation }\end{array}$ & $\begin{array}{l}\text { Optimisation of } \\
\text { cardiac, respiratory, } \\
\text { renal disease, } \\
\text { diabetes. }\end{array}$ \\
\hline Medication & Medication review & $\begin{array}{l}\text { Rationalisation; } \\
\text { STOPP-START } \\
\text { criteria }\end{array}$ \\
\hline Nutrition & Modified MUST tool & $\begin{array}{l}\text { Nutritional } \\
\text { optimisation; } \\
\text { dietician referral }\end{array}$ \\
\hline Exercise tolerance & $\begin{array}{l}\text { Metabolic Equivalents } \\
\text { Scale }\end{array}$ & $\begin{array}{l}\text { Prehabilitation } \\
\text { programme }\end{array}$ \\
\hline Cognition & $\begin{array}{l}\text { Montreal Cognitive } \\
\text { Assessment }\end{array}$ & $\begin{array}{l}\text { Delirium risk } \\
\text { reduction protocols }\end{array}$ \\
\hline Frailty & $\begin{array}{l}\text { Reported Edmonton } \\
\text { Frail Scale }\end{array}$ & $\begin{array}{l}\text { Multicomponent } \\
\text { CGA intervention }\end{array}$ \\
\hline Mood & $\begin{array}{l}\text { Depression question; } \\
\text { global assessment }\end{array}$ & $\begin{array}{l}\text { Antidepressants; } \\
\text { referral to clinical } \\
\text { psychology }\end{array}$ \\
\hline $\begin{array}{l}\text { Functional } \\
\text { capacity }\end{array}$ & $\begin{array}{l}\text { Nottingham Extended } \\
\text { Activities of Daily } \\
\text { Living }\end{array}$ & $\begin{array}{l}\text { Social services } \\
\text { referral }\end{array}$ \\
\hline $\begin{array}{l}\text { Social } \\
\text { circumstances }\end{array}$ & $\begin{array}{l}\text { Housing, support } \\
\text { network, existing care } \\
\text { arrangements }\end{array}$ & $\begin{array}{l}\text { Social services } \\
\text { referral }\end{array}$ \\
\hline Discharge plan & $\begin{array}{l}\text { Identification } \\
\text { of borough, } \\
\text { rehabilitation facilities } \\
\text { and access to social } \\
\text { services support. } \\
\text { Explanation to patient } \\
\text { and family }\end{array}$ & $\begin{array}{l}\text { Early OT and } \\
\text { Physiotherapy } \\
\text { referral }\end{array}$ \\
\hline $\begin{array}{l}\text { Screening } \\
\text { investigations } \\
\text { (where indicated) }\end{array}$ & $\begin{array}{l}\text { FBC, renal, liver, } \\
\text { bone, thyroid profiles, } \\
\text { haematinics, Vitamin } \\
\text { D, ECG, CXR, BNP, } \\
\text { HbA1c. }\end{array}$ & $\begin{array}{l}\text { Diagnosis } \\
\text { of medical } \\
\text { comorbidity and } \\
\text { preoperative } \\
\text { optimisation }\end{array}$ \\
\hline
\end{tabular}

$\mathrm{BNP}=$ brain natriuretic peptide; $\mathrm{CGA}=$ Comprehensive Geriatric Assessment; CXR = chest $X$-ray; $E C G$ = electrocardiogram; $F B C=$ full blood count; $\mathrm{HbA1}$ = haemoglobin A1c; MUST = malnutrition universal screening tool; OT = occupational therapist; STOPP-START = Screening Tool of Older Person's Prescriptions - Screening Tool to Alert doctors to Right Treatment

members to resolve these issues. Projected discharge dates for all surgical patients are established alongside enhanced recovery principles.

4 Inpatient subacute care and rehabilitation

Selected patients whose recovery is complicated by medical complications or increased rehabilitation needs have access to a geriatrician-led surgical rehabilitation ward. This ward predates the establishment of the surgical liaison service and also serves orthopaedics, trauma and vascular surgical teams. It provides a subacute location and 'takeover service' for ongoing medical care and rehabilitation. This facilitates transfer of subacute patients out of the acute surgical bed base. Although parent surgical teams retain responsibility for surgical aspects of care and emergency out-of-hours cover, day-to-day inpatient care and discharge planning is delivered by the geriatric surgical liaison team. Surgical teams review where needed on an as-required basis.

\section{Team structure}

The surgical liaison team is led by a consultant geriatrician. On a weekly basis, three direct clinical care (DCC) programmed activities (PAs) are allocated to embedded liaison and one DCC to the preoperative CGA clinic.

The consultant physician is supported by - and trains - junior medical staff based on the surgical rehabilitation ward. Patients are formally 'taken over' from their parent surgical team when transferred to this ward. This team of junior doctors has its origins in the orthogeriatrics service and predates establishment of the surgical liaison service. It is not a new resource. The team consists of a full time medical specialty trainee (ST3-7); full time medical core trainee (CT1-2), and three foundation doctors (FY1). The existing team of surgical allied healthcare professionals supports the rehabilitation and discharge of patients under the surgical liaison service.

\section{Study of the intervention}

The service development was conducted at a tertiary referral surgical centre and major trauma unit in inner London. The hospital contains 287 beds, of which 37 are allocated to acute general and gastrointestinal surgery. In view of the existing evidence base for this type of liaison service, ethical approval was not required. 'Model for improvement' quality methodology was employed, incorporating 'plan, do, study, act' cycles. Although the data and evaluation presented in this paper represent the first evaluation of LOS, smaller cycles were deployed to evaluate the practicality of each of the constituent parts (eg outpatient clinic, inpatient reviews, and discharge planning by multidisciplinary teams [MDTs]). Interim meetings were held with key stakeholders to discuss issues, identify problems and suggest solutions. Some examples are illustrated in Table 2. Before-andafter analysis was employed in the evaluation of the service's impact on LOS.

\section{Data collection}

All surgical admissions to the general surgical ward aged over 60 years were retrospectively identified during an 8-month period (January - August 2014) prior to the service implementation using trust data. Following implementation of the service, data were collected for 13 months (September 2014 to October 2015 inclusive). Electronic case note reviews were conducted to confirm the eligibility of patients for inclusion. All elective and emergency general surgical admissions were included in the analysis. Although not denied access to the liaison service, non-surgical patients outlying on the general surgical ward were excluded from the analysis due to concerns that data capture for outliers was unreliable and may have introduced excess bias. Similarly, 
Table 2. Example implementation problems and solutions identified through PDSA cycles

\begin{tabular}{|c|c|c|}
\hline Problems identified & Root cause & Solutions \\
\hline $\begin{array}{l}\text { Patients potentially } \\
\text { benefitting from } \\
\text { preoperative clinic } \\
\text { not being referred }\end{array}$ & $\begin{array}{l}\text { Initial selection } \\
\text { of patients using } \\
\text { frailty screening } \\
\text { unsuccessful } \\
\text { CNS and surgeons } \\
\text { did not have time } \\
\text { to screen older } \\
\text { patients for frailty }\end{array}$ & $\begin{array}{l}\text { Move to open access } \\
\text { referral on basis of } \\
\text { perceived frailty and } \\
\text { multimorbidity }\end{array}$ \\
\hline $\begin{array}{l}\text { Insufficient } \\
\text { outpatient clinic } \\
\text { capacity, delays in } \\
\text { seeing patients }\end{array}$ & $\begin{array}{l}\text { Increase in } \\
\text { referrals }\end{array}$ & $\begin{array}{l}\text { Liaison with } \\
\text { outpatient lead nurse } \\
\text { to provide clinical } \\
\text { space for SpR to join } \\
\text { clinic and run parallel } \\
\text { clinic lists }\end{array}$ \\
\hline $\begin{array}{l}\text { Inadequate } \\
\text { information sharing }\end{array}$ & $\begin{array}{l}\text { Letters not reliably } \\
\text { incorporated into } \\
\text { paper notes in } \\
\text { time for surgery }\end{array}$ & $\begin{array}{l}\text { Clinic letters emailed } \\
\text { to all stakeholders } \\
\text { and uploaded to } \\
\text { electronic database } \\
\text { (and subsequently } \\
\text { electronic case } \\
\text { notes) }\end{array}$ \\
\hline \multirow[t]{2}{*}{$\begin{array}{l}\text { Inpatients } \\
\text { potentially } \\
\text { benefitting from } \\
\text { medical review } \\
\text { excluded by age }\end{array}$} & \multirow[t]{2}{*}{$\begin{array}{l}\text { Junior members of } \\
\text { the surgical team } \\
\text { considered only } \\
\text { older patients for } \\
\text { inpatient review }\end{array}$} & $\begin{array}{l}\text { Clearer } \\
\text { communication of } \\
\text { the role of service } \\
\text { to junior surgical } \\
\text { doctors }\end{array}$ \\
\hline & & $\begin{array}{l}\text { Presence at surgical } \\
\text { induction to explain } \\
\text { role of service }\end{array}$ \\
\hline \multirow{2}{*}{$\begin{array}{l}\text { Variable } \\
\text { attendance of } \\
\text { junior doctors at } \\
\text { discharge planning } \\
\text { MDT meeting }\end{array}$} & \multirow{2}{*}{$\begin{array}{l}\text { Timing clashed } \\
\text { with the heaviest } \\
\text { burden of post- } \\
\text { ward round jobs }\end{array}$} & $\begin{array}{l}\text { Timing of meeting } \\
\text { moved }\end{array}$ \\
\hline & & $\begin{array}{l}\text { Senior surgical } \\
\text { support enlisted } \\
\text { to emphasise } \\
\text { importance of } \\
\text { attendance }\end{array}$ \\
\hline
\end{tabular}

surgical patients outlying on other wards were excluded from the analysis, but not denied access to the service. Demographic and inpatient LOS data were collected for all patients. No other known confounding changes to surgical service delivery took place during the evaluation period.

To characterise clinical activity at inpatient review, data describing medical interventions were collected prospectively in the first 9 months of the service.

\section{Data evaluation}

Patient characteristics were collated and included sex, age, type of admission and whether surgery was performed. Length of stay in pre- and post-intervention groups was evaluated using
Table 3. Demographics of surgical population before and after service implementation

$\begin{array}{llll} & \text { Pre-service } & \text { Post-service } & \text { p-value } \\ \begin{array}{l}\text { Mean age in years } \\ \text { (range) }\end{array} & 72.7(60-100) & 72.8(60-94) & 0.430 \\ \begin{array}{l}\text { Patients undergoing } \\ \text { surgery }\end{array} & \mathrm{n}=112(55 \%) & \mathrm{n}=292(61 \%) & 0.173 \\ \begin{array}{l}\text { Patients undergoing } \\ \text { minimally invasive }\end{array} & \mathrm{n}=50(45 \%) & \mathrm{n}=155(53 \%) & 0.219 \\ \begin{array}{l}\text { surgery } \\ \end{array} & & \\ \end{array}$

Mann-Whitney $U$ tests. Subgroup analysis was performed to examine whether older patients in particular gained greater benefit. Mood's median rank testing showed similar levels of sensitivity confirming the robustness of our analysis.

\section{Results}

Our data capture identified 720 admissions to the general surgical ward during the analysis period. Missing data were present in $5.2 \%(n=38)$; these were excluded. Therefore, the data analysis includes a total of 682 patients; 203 pre-intervention and 479 post-intervention.

Patient characteristics before and after intervention were closely matched (Table 3).

\section{Preoperative CGA clinic}

In the 13-month intervention period, 132 patients were referred for preoperative CGA. Eighty patients (60\%) had resectable colorectal tumours; 32 oesophagogastric tumours (24\%). The remaining $16 \%$ were drawn from benign general surgery $(n=11)$, urology $(n=3)$, orthopaedics $(n=3)$, and ophthalmology $(n=1)$. Of patients undergoing pre-operative CGA, 36\% $(n=48)$ did not proceed to surgery following assessment. Change in disease status $(n=9)$, refusal of surgery $(n=3)$ and death $(n=1)$ accounted for $10 \%$ of patients not undergoing surgery following CGA; the remaining $26 \%$ were determined to be unfit following assessment $(n=35)$.

\section{Inpatient activity}

In the first 9 months of the service 233 inpatient reviews were conducted on surgical patients at the request of the surgical team. Table 4 categorises the underlying indications for medical review.

\section{Length of stay}

The implementation of this service has been associated with significant reductions in LOS (Table 5, Figs 2-4). For all surgical admissions included in this study, mean LOS was reduced by 3.1 days ( $95 \%$ CI $0.7-5.5, p=0.007)$. Subgroup analysis in patients aged $60-74$ revealed mean LOS reduction 3.2 days ( $95 \%$ CI $0.31-6.4, p=0.061)$; in patients aged $>75$ mean LOS reduction was 3 days ( $95 \%$ CI $0.2-5.8, p=0.045$ ).

Emergency surgical admissions were also associated with a reduction in mean LOS by 4.4 days (95\% CI 1.5-7.2, $p=0.005$ ). Subgroup analysis in patients aged $60-74$ showed mean reduction 


\begin{tabular}{|c|c|}
\hline Perioperative medical issues addressed & $\begin{array}{l}\text { Percentage of } \\
\text { patients }\end{array}$ \\
\hline Fluid balance (CCF; AKI) & $20.1 \%(n=48)$ \\
\hline Cardiology (arrhythmia; ischaemia) & $16.7 \%(n=39)$ \\
\hline Delirium & $16.3 \%(n=38)$ \\
\hline Respiratory (HAP; PE; pleural effusion) & $14.6 \%(n=34)$ \\
\hline Sepsis & $13.3 \%(n=31)$ \\
\hline $\begin{array}{l}\text { Gastroenterology (constipation; colitis; hepatitis; } \\
\text { decompensated chronic liver disease) }\end{array}$ & $7.3 \%(n=17)$ \\
\hline $\begin{array}{l}\text { Haematology (anaemia; coagulation; } \\
\text { thrombocytopaenia) }\end{array}$ & $7.3 \%(n=17)$ \\
\hline Endocrinology (electrolyte derangement; diabetes) & $6.9 \%(n=16)$ \\
\hline Neurology (seizures; stroke; TIA) & $2.6 \%(n=6)$ \\
\hline Medication rationalisation & $11.6 \%(n=27)$ \\
\hline Pain management & $1 \%(n=3)$ \\
\hline Nutritional optimisation & $7.7 \%(n=18)$ \\
\hline Communication with family & $30.5 \%(n=71)$ \\
\hline $\begin{array}{l}\text { Surgical HDU review (vasopressors; NIV } \\
\text { supervision) }\end{array}$ & $23.6 \%(n=55)$ \\
\hline $\begin{array}{l}\text { De-escalation (removal of lines; catheters; } \\
\text { therapeutics) }\end{array}$ & $15 \%(n=35)$ \\
\hline Discharge planning & $48.1 \%(n=112)$ \\
\hline
\end{tabular}

in LOS 5.5 days (95\% CI 0.52-11.1, $p=0.019$ ); in patients aged $>75$ mean LOS reduction was 2.75 days ( $95 \%$ CI $-0.1-5.6, p=0.091$ ).

In patients admitted electively for gastrointestinal cancer surgery, LOS reductions did not reach statistical significance during the study period; although, a trend reduction was seen indicating possibly greater LOS reduction with advancing age (mean reduction LOS aged $60-74$ years 1.3 days, $p=0.701$; aged $>755.2$ days, $p=0.099)$. This reduction was most prominent in patients aged $>75$ years at 5.2 days $(95 \%$ CI $-1.7-12.1, p=0.099)$. In the subgroup aged $60-74$ years a non-significant increase in mean LOS was observed of 1.3 days (95\% CI -3.2-2.1, $p=0.701$ ).

Dixon's Q testing did demonstrate possible statistical outliers. However, these represent patients with medical complexity and challenging discharge. These patients are a small but important part of modern surgical caseload. We consider these patients to be potential beneficiaries of a service development such as this. It was therefore felt to be inappropriate to exclude them from our analysis.

\section{Discussion}

\section{Reductions in LOS}

These data in Table 5 indicate that the establishment of an embedded geriatric surgical liaison service within acute general and gastrointestinal surgery may be associated with significant reductions in inpatient LOS. Evidence from other sources has previously indicated that similar models of care can reduce complications and LOS in orthopaedic, urological and vascular surgical cohorts. ${ }^{15,20,21}$ However, limited evidence has previously been published to demonstrate that the model of care can be successfully transferred to gastrointestinal surgery. Importantly, these data may indicate the potential value of this model of care to emergency general surgical services. Patients admitted with acute surgical pathology are frequently frail, multimorbid and critically ill. Recognition of the need for collaborative models of care between medicine and surgery has been made by the National Emergency Laparotomy Audit. ${ }^{11}$

Note is made of the non-significant increase in LOS for younger patients undergoing elective surgery. Although full demographic data are not available to qualify this observation, it should be noted that one of the aims of this service has been to increase access to surgery for frail and comorbid patients through delivery of embedded medical support in the perioperative period. We speculate that such an increase in LOS could be explained by an increase in surgical patient complexity after implementation of the service.

\section{Diversity of medical complications}

The descriptive data in Table 4 indicate the wide range of medical complications that general surgical patients are vulnerable to in the perioperative period. Notably, many individual patients suffer from multiple complications affecting different systems. Under conventional services, these patients often require referral to multiple specialist teams, each of whom tends to review their system in isolation. An advantage of the embedded general physician is their ability to address standard GIM pathologies holistically. In the absence of GIM training, it is unlikely that the breadth of medical postoperative pathology can be fully met by anaesthetists.

\section{Preoperative comprehensive geriatric assessment}

Although preoperative optimisation through CGA is an integral component to this service, not all older surgical admissions were referred for preoperative CGA. Furthermore, of all patients undergoing preoperative CGA, $26 \%$ were determined to be unfit by the surgical MDT on the basis of their risk assessment. This may reflect the role of preoperative CGA in enhancing standard pre-assessment processes through new diagnosis of comorbidity and geriatric syndromes such as frailty and cognitive impairment. Furthermore, enhanced risk assessment through CGA may help to justify potentially contentious decisions regarding non-surgical treatment of cancer in patients considered to be at excess risk of surgical intervention.

Our analysis has not aimed to delineate differences in outcome between planned admissions receiving CGA versus those who did not. The reasons for this are the myriad confounders inherent in the clinic population; by definition this selects the most frail and comorbid, and so poorer outcomes would be expected in this subgroup.

\section{Value of embedded post-operative liaison}

Although we consider the preoperative CGA clinic to add to the quality of care of selected patients (including those who do not 
Table 5. Mean length of stay (LOS) before and after service implementation

\begin{tabular}{|c|c|c|c|c|c|}
\hline & & Pre-service & Post-service & $\begin{array}{l}\text { Mean LOS reduction ( } 95 \% \\
\text { confidence interval) }\end{array}$ & $\begin{array}{l}\text { Mann-Whitney U test } \\
\text { (Mood's median test) }\end{array}$ \\
\hline \multirow[t]{7}{*}{ All GI surgery } & Mean & 10.6 & 7.5 & 3.1 & 0.007 \\
\hline & SD & 16.2 & 9.7 & $(0.7-5.5)$ & $(0.07)$ \\
\hline & Range & 122 & 96 & & \\
\hline & $95 \% \mathrm{CI}$ & $8.3-12.8$ & $6.6-8.3$ & & \\
\hline & Median & 6 & 5 & & \\
\hline & Interquartile & 9 & 6 & & \\
\hline & Number & 203 & 479 & & \\
\hline \multirow[t]{7}{*}{ Ages $60-74$ years } & Mean & 10.8 & 7.6 & 3.2 & 0.061 \\
\hline & SD & 18.7 & 10.8 & $(0.31-6.4)$ & $(0.037)$ \\
\hline & Range & 122 & 96 & & \\
\hline & $95 \% \mathrm{CI}$ & $7.4-14.1$ & $6.3-8.8$ & & \\
\hline & Median & 6.0 & 5.0 & & \\
\hline & Interquartile & 7.75 & 6 & & \\
\hline & Number & 124 & 290 & & \\
\hline \multirow[t]{7}{*}{ Age $\geq 75$ years } & Mean & 10.3 & 7.2 & 3 & 0.045 \\
\hline & SD & 11.3 & 7.9 & $(0.2-5.8)$ & $(0.115)$ \\
\hline & Range & 62 & 54 & & \\
\hline & $95 \% \mathrm{CI}$ & $7.7-12.8$ & $6.1-8.4$ & & \\
\hline & Median & 6 & 5 & & \\
\hline & Interquartile & 9 & 7 & & \\
\hline & Number & 79 & 189 & & \\
\hline \multirow[t]{7}{*}{ Emergency GI surgery } & Mean & 11.1 & 6.7 & 4.4 & 0.005 \\
\hline & SD & 18.4 & 9.6 & $(1.5-7.2)$ & $(0.003)$ \\
\hline & Range & 122 & 96 & & \\
\hline & $95 \% \mathrm{CI}$ & $8.0-14.2$ & $5.5-7.9$ & & \\
\hline & Median & 6.0 & 4.0 & & \\
\hline & Interquartile & 9.0 & 5.0 & & \\
\hline & Number & 137 & 237 & & \\
\hline \multirow[t]{7}{*}{ Ages 60-74 years } & Mean & 12.5 & 6.9 & 5.5 & 0.019 \\
\hline & SD & 22.6 & 9.6 & $(0.52-11.1)$ & $(0.019)$ \\
\hline & Range & 122 & 96 & & \\
\hline & $95 \% \mathrm{CI}$ & $7.4-17.5$ & $5.1-8.9$ & & \\
\hline & Median & 6 & 4 & & \\
\hline & Interquartile & 9 & 5 & & \\
\hline & Number & 80 & 236 & & \\
\hline \multirow[t]{7}{*}{ Age $\geq 75$ years } & Mean & 9.0 & 6.3 & 2.75 & 0.091 \\
\hline & SD & 9.5 & 6.7 & $(-0.1-5.6)$ & (0.109) \\
\hline & Range & 42 & 41 & & \\
\hline & $95 \% \mathrm{CI}$ & $6.6-11.6$ & $5.0-7.7$ & & \\
\hline & Median & 6 & 4 & & \\
\hline & Interquartile & 8 & 6 & & \\
\hline & Number & 57 & 99 & & \\
\hline Elective GI surgery & Mean & 9.5 & 8.2 & 1.3 & 0.189 \\
\hline
\end{tabular}


Table 5. (Continuted)

\begin{tabular}{|c|c|c|c|c|c|}
\hline & & Pre-service & Post-service & $\begin{array}{l}\text { Mean LOS reduction ( } 95 \% \\
\text { confidence interval) }\end{array}$ & $\begin{array}{l}\text { Mann-Whitney U test } \\
\text { (Mood's median test) }\end{array}$ \\
\hline & SD & 10.6 & 9.8 & $(-1.4-4.03)$ & \\
\hline & Range & 61.0 & 82 & & \\
\hline & $95 \% \mathrm{CI}$ & $76.9-12.1$ & $7.0-9.5$ & & \\
\hline & Median & 6 & 6 & & \\
\hline & Interquartile & 7 & 7 & & \\
\hline & Number & 66 & 242 & & \\
\hline Ages $60-74$ years & Mean & 7.7 & 8.2 & 1.3 & 0.701 \\
\hline & SD & 6.8 & 10.3 & $(-3.2-2.1)$ & $(0.947)$ \\
\hline & Range & 37 & 81 & & \\
\hline & $95 \% \mathrm{CI}$ & $5.6-9.7$ & $6.5-9.9$ & & \\
\hline & Median & 6 & 6 & & \\
\hline & Interquartile & 4.75 & 7 & & \\
\hline & Number & 44 & 152 & & \\
\hline Age $\geq 75$ years & Mean & 13.3 & 8.1 & 5.2 & 0.099 \\
\hline & SD & 15.1 & 8.9 & $(-1.7-12.1)$ & $(0.186)$ \\
\hline & Range & 61 & 54 & & \\
\hline & $95 \% \mathrm{CI}$ & $6.7-20.0$ & $6.3-10.0$ & & \\
\hline & Median & 8 & 6 & & \\
\hline & Interquartile & 9.5 & 7.5 & & \\
\hline & Number & 22 & 84 & & \\
\hline
\end{tabular}

undergo surgery), these data indicate that significant service improvements can be achieved through embedded inpatient liaison alone. A mean reduction in LOS of 4.4 days for emergency surgical admissions aged $>60$ years illustrates the importance of proactive inpatient management of medical complications and comorbidity; it also supports the processes of rigorous multidisciplinary discharge planning. It is therefore possible that the benefits of this model

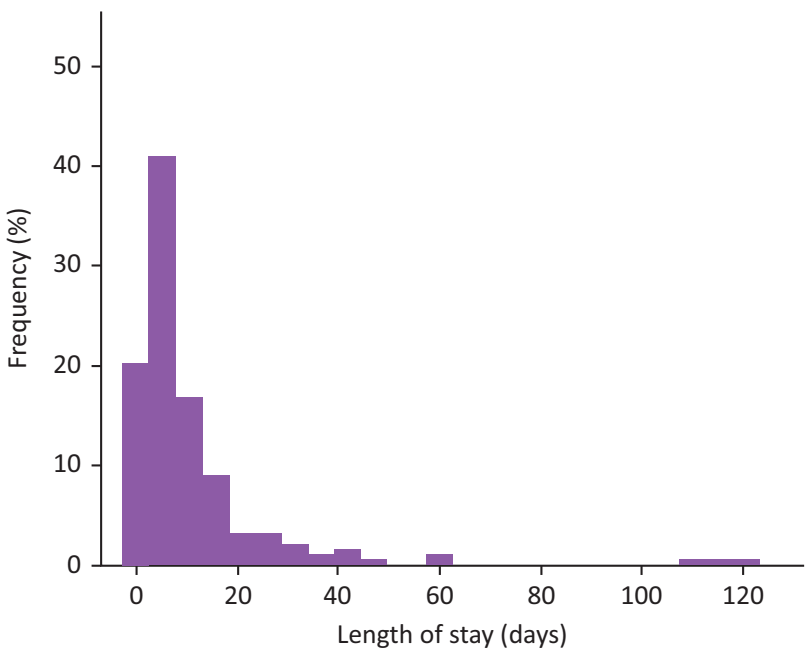

Fig 2. Mean length of stay before introduction of service. might be achievable even if local resources did not permit the establishment of a preoperative CGA clinic.

\section{Post-surgical rehabilitation}

Furthermore, although access to the rehabilitation ward is advantageous to a few selected patients, it is not integral to

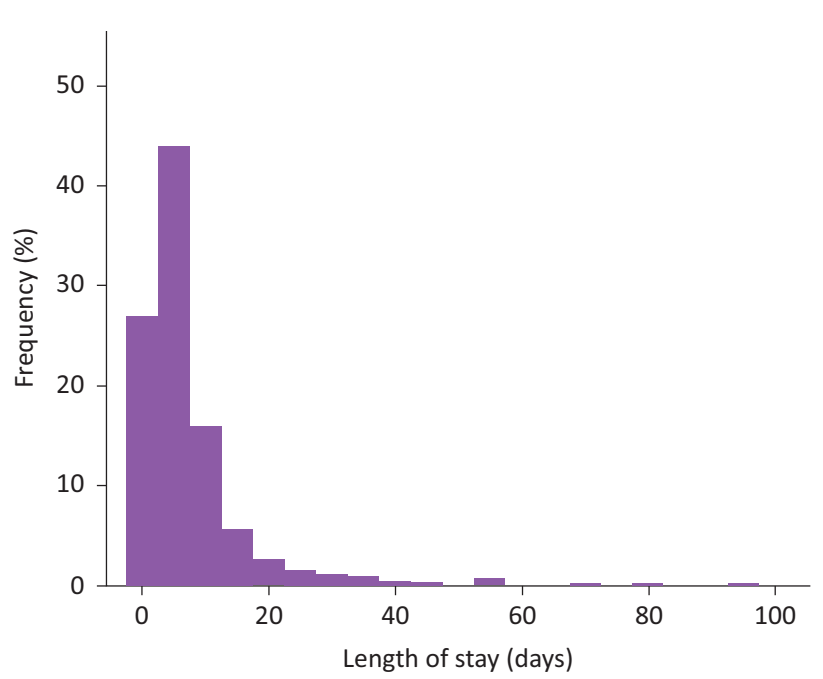

Fig 3. Mean length of stay after introduction of service. 


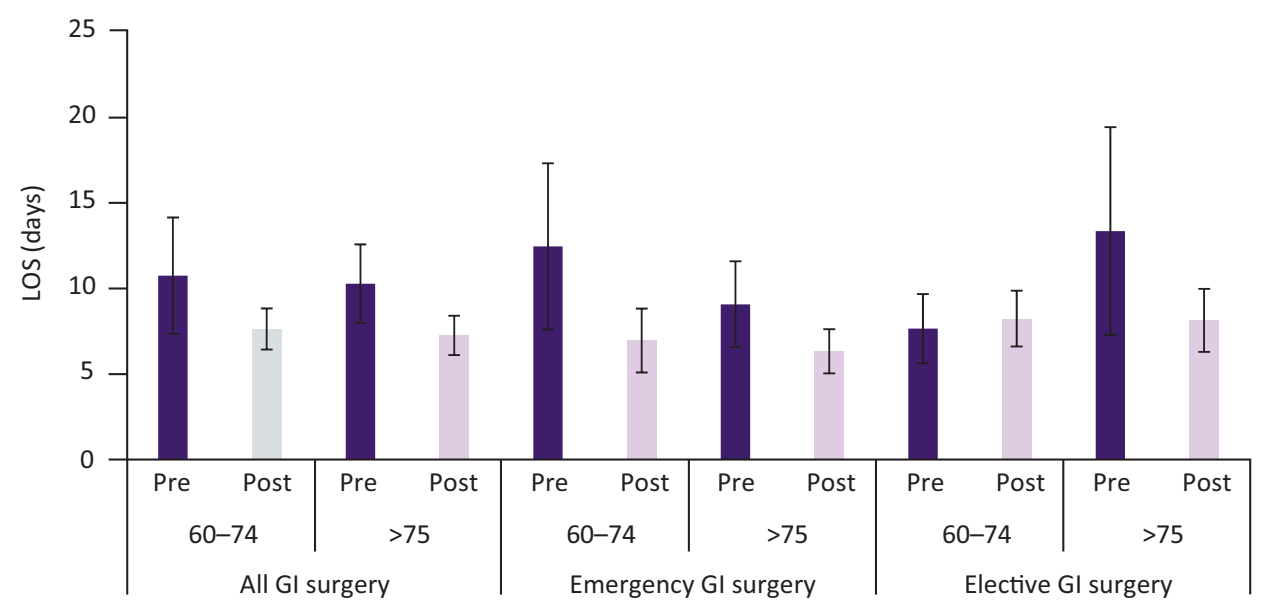

Fig 4. Mean length of stay (LOS) pre- and post-service implementation, divided by subgroup. GI = gastrointestinal the wider service. In comparison to lower limb trauma and orthopaedics, few general surgical patients require protracted inpatient rehabilitation. The absence of this facility should therefore not be considered a barrier to reproduction of this model in other centres. In our experience, many centres would be able to accommodate these few selected patients in existing rehabilitation or geriatric medicine services.

\section{Economic viability}

Although establishment of this service required the allocation of four PAs of consultant time, other staffing was drawn from existing sources and required no additional investment. Although economic analysis is complex, a simplistic analysis based on LOS reduction can be achieved using NHS quality improvement methodology. ${ }^{22}$ This reveals that a mean LOS reduction of 3.1 days per case may be associated with cost savings of approximately $£ 300,000$ per annum (although with a confidence interval of $0.7-5.5$ days, this value could lie approximately between $£ 75,000$ and $£ 590,000$ ). We therefore believe that this investment in consultant time is likely to be economically justified, even in times of financial constraint. This conclusion is made without considering other opportunity savings that may emerge as a result of improved inpatient care and flow.

\section{Limitations}

We recognise that the methodology behind this study has weaknesses and that confounding factors may account for the observed reductions in LOS in our unadjusted analysis. Although no other reconfigurations to surgical services are known to have coincided with establishment of this liaison service, it is possible other surgical factors we have not accounted for may contribute. Although not statistically significant, a trend increase was seen in minimally invasive surgery following intervention, which may have contributed to reduced LOS. However, a trend rise in the proportion of patients requiring surgery was also seen, perhaps indicating increased severity of illness post intervention. Time and resource constraints did not permit detailed evaluation of individual comorbidities or complications in the 682 patients included in the study period. Differences in comorbidity or complication profile could therefore account for variations in LOS before and after service implementation.

\section{Conclusions}

Despite the limitations described above, this service development has been associated with significant reductions in surgical inpatient LOS. Notably, it is among the first published data indicating that geriatric surgical liaison may be effective at reducing LOS in acute general and gastrointestinal surgery. Further research is required to determine whether reduced complications and delayed discharges account for this observation.

This study indicates that liaison models of care can be established with modest, economically viable investment, and may be able to achieve clinically relevant results within the timeframe of a 1-year pilot. These results can lead to substantive long term funding and sustainability. This service development may therefore be applicable to other centres aiming to address the challenges of their ageing surgical populations.

\section{Note}

Dr David Shipway was based at Imperial College Healthcare NHS Trust as consultant physician during the research, writing and submission of this paper.

\section{References}

1 United Nations, D.o.E.a.S.A., Population Division, World Population Ageing. 2015.

2 Barnett K, Mercer SW, Norbury M et al. Epidemiology of multimorbidity and implications for health care, research, and medical education: a cross-sectional study. Lancet 2012;380:37-43.

3 Fried LP, Tangen CM, Walston ] et al. Frailty in older adults: evidence for a phenotype. J Gerontol A Biol Sci Med Sci 2001;56:M146-157.

4 Royal College of Surgeons. Access all ages: Assessing the impact of age on access to surgical treatment. London: RCS England, 2012.

5 National Cancer Intelligence Network. Major surgical resections England, 2006-2010. London: 2014. www.ncin.org.uk/about_ncin/ major_resections

6 Shipway DJH, Partridge JSL, Foxton CR et al. Do surgical trainees believe they are adequately trained to manage the ageing 
population? A UK survey of knowledge and beliefs in surgical trainees. J Surg Educ 2015;72:641-7.

7 Polanczyk CA, Marcantonio E, Goldman L et al. Impact of age on perioperative complications and length of stay in patients undergoing non-cardiac surgery. Ann Intern Med 2001;134:637-43.

8 Partridge JSL, Harari D, Dhesi JK. Frailty in the older surgical patient: a review. Age Ageing 2012;41:142-7.

9 National Confidential Enquiry into Patient Outcome and Death. Knowing the risk: a review of the perioperative care of surgical patients. London: NCEPOD, 2011.

10 National Confidential Enquiry into Patient Outcome and Death. An Age Old Problem. A review of the care received by elderly patients undergoing surgery. London: NCEPOD, 2010.

11 NELA Project Team. Second Patient Report of the National Emergency Laparotomy Audit. London: RCoA, 2016.

12 Royal College of Physicians. Future hospital: caring for medical patients. London: RCP, 2013.

13 Oliver D, Foot C, Humphries R. Making our health and care systems fit for an ageing population. London: The King's Fund, 2014.

14 McAleese P, Odling-Smee W. The effect of complications on length of stay. Ann Surg 1994;220:740-4.

15 Harari D, Hopper A, Dhesi ] et al. Proactive care of older people undergoing surgery ('POPS'): designing, embedding, evaluating and funding a comprehensive geriatric assessment service for older elective surgical patients. Age Ageing 2007;36:190-6

16 Partridge JSL, Harari D, Martin FC et al. The impact of pre-operative comprehensive geriatric assessment on postoperative outcomes in older patients undergoing scheduled surgery: a systematic review. Anaesthesia 2014;69:8-16.
17 British Orthopaedic Association, British Geriatrics Society. Care of patients with fragility fractures. London: BOA, 2007.

18 Ellis G, Whitehead MA, Robinson D, O'Neill D, Langhorne P. Comprehensive geriatric assessment for older adults admitted to hospital: meta-analysis of randomised controlled trials. BMJ 2011;343:d6553.

19 Stuck AE, Siu AL, Wieland GD, Adams J, Rubenstein LZ. Comprehensive geriatric assessment: a meta-analysis of controlled trials. Lancet 1993:342:1032-6.

20 Braude P, Goodman A, Elias T et al. Evaluation and establishment of a ward-based geriatric liaison service for older urological surgical patients: Proactive care of Older People undergoing Surgery (POPS)-Urology. BJU Int 2017;120:123-9.

21 Partridge JSL, Harari D, Martin FC et al. Randomised clinical trial of comprehensive geriatric assessment and optimization in vascular surgery. Br J Surg 2017;104:679-87.

22 NHS Institute for Innovation and Improvement. Quality and Service Improvement Tools. Length of Stay - Reducing Length of Stay. NHS Institute for Innovation and Improvement, 2008. http://webarchive.nationalarchives.gov.uk/20121116072838/ https://www.institute.nhs.uk/quality_and_service_improvement_ tools/quality_and_service_improvement_tools/length_of_stay.html [Accessed 29 December 2017].

Address for correspondence: Dr David Shipway, North Bristol NHS Trust, Southmead Road, Bristol BS10 5NB, UK.

Email: shipway@doctors.net.uk

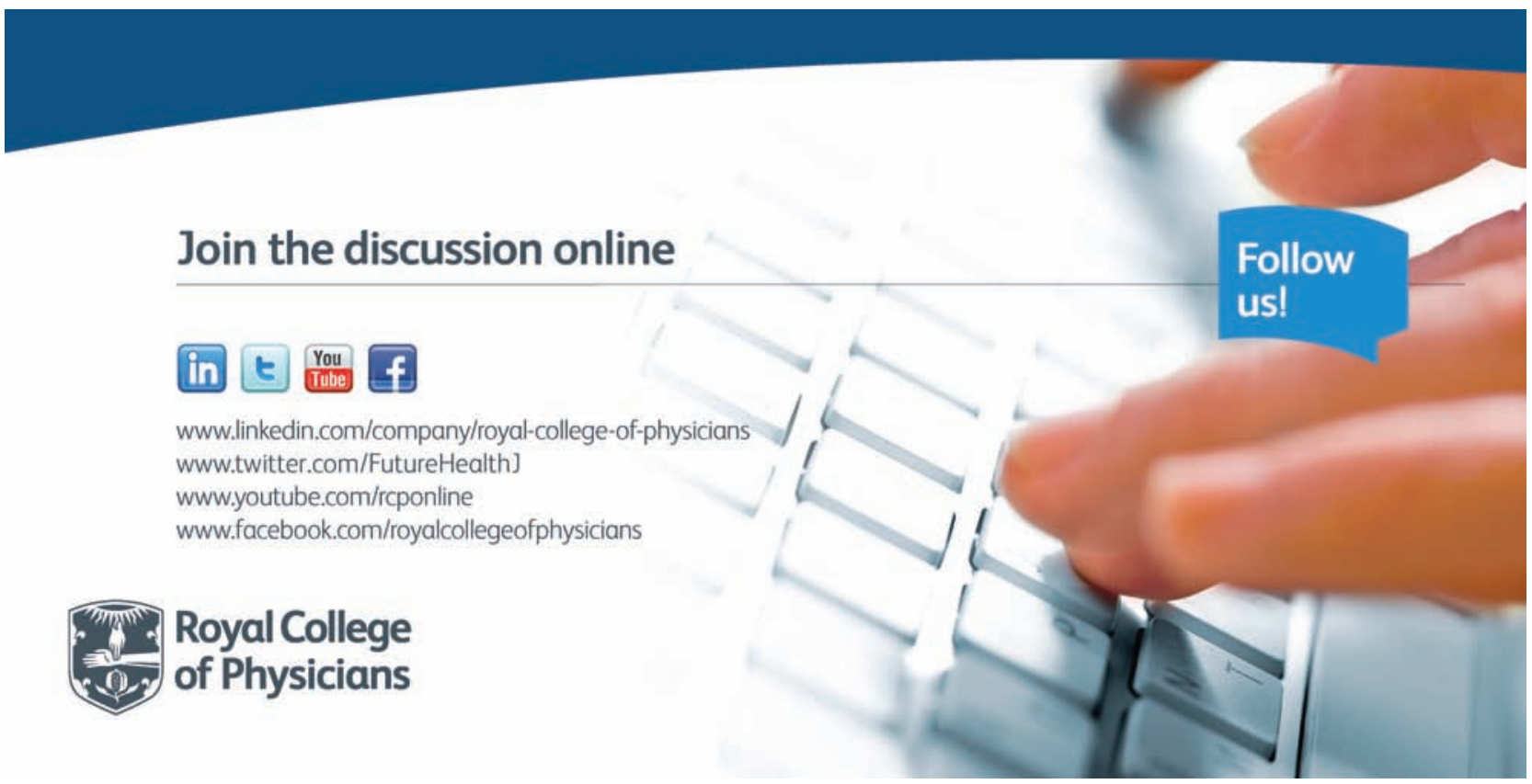

